(relieved by lying down) and a certain degree of excitability and irritability are prominent symptoms. Sight, hearing, taste and smell are normal; memory good. The patient can make purchases. There is want of power to arrange words in grammatical sequence. Though he says he cannot, he can write at dictation when given word for word, sometimes mistaking occasionally $c$ for $d$ and an $a$ for a $b$. Volitional writing is impaired and almost entirely lost, except writing his own name. His understanding of printed language is good, and reading aloud normal, as is the faculty of copying words.

L. F. B.

\title{
BERI - BERI IN THE PROVINCETOWN GRAND FISHING BANK FLEET.
}

In the "Boston Medical and Surgical Journal," November I 3,1890, Dr. W. S. Birge reports seven cases of beriberi among the fishing fleet that returned from the Grand Banks in the fall of 1889 . The disease does not often originate so far north. Its undoubted cause in this instance was defective nourishment, the salt beef being of poorer quality than usual and the supply of fresh provisions most meagre. Dampness and cold, that are always present on the Grand Banks, would undoubtedly act as factors in developing the disorder in a system impoverished and rendered anæmic from a diet at once unwholesome and deficient in nitrogenous principles. The catch of fish was at irregular intervals, so that fresh fish as food was of rare occurrence.

The sufferers were all naturally strong, able-bodied men, without previous trace of constitutional disturbance. The prominent symptoms in each were general œdema, dyspnœe with precordial distress, numbness of the lower extremities, with a peculiar shuffing gait, showing marked inability to lift the leg at the knee. In three cases there was enlargement of the spleen.

Treatment consisted chiefly in the use of a mixed diet, composed of coarsely prepared grains and a liberal allowance of fresh beef, of diuretics and hydragogue cathartics in marked dropsical effusion, together with digitalis and the administration of tincture of chloride of iron and iodide of potassium.

L. F. B.

DRUMMER'S PALSI-PARESIS OF THE LEFT FLEXOR LONGUS POLLICIS.

Dr. Ludwig Bruns (Neurol. Centralbl., June 1 5, I 890 ) has 
added a new variety to our list of occupation neuroses or palsies. The case he reports is that of a drummer of an infantry regiment, who was first seen by him March 28, I 890 . The patient had already served one year as a soldier under arms. In October, I889, he became a drummer, and was accustomed to practice about five hours a day.

Until the beginning of March. 1890 , he experienced no trouble, but at that time he began to have occasional slight pains in his left forearm and ball of the left thumb. Some two weeks later the left thumb suddenly became immovable while he was drumming. He was at once seen by the regimental surgeon, and later, on March $28 \mathrm{th}$, by Bruns, who noted the following condition: There was complete paralysis of the left. flexor longus pollicis, the patient being otherwise healthy and powerful. He was totally unable to flex the last phalanx of the left thumb, and could oppose no resistance whatever to passive movements of extension. The functions of the left hand were otherwise but little affected. The patient was able to hold small objects between the thumb and fingers, and even pick up a needle with thumb and forefinger, but he could not hold the drumstick firmly.

There was no response to either faradic or galvanic current in the muscle of the flexor longus pollicis. On applying the battery to the median nerve at the elbow, the last phalanx of the thumb remained in extension, though all the other muscles supplied by the nerve contracted promptly. Bruns thought there was possibly a slight weakness of the adductor pollicis, but it contracted at once when the ulnar nerve was stimulated at the wrist. 'Sensation was everywhere good, and the patient complained of no pain.

Treatment consisted of galvanism and massage. By the middle of May the patient could flex slightly the last plalanx of the thumb, but the electrical condition remained the same as before.

In discussing the symptomatology and pathology of the above case, Bruns shows clearly what nuscles are chiefly concerned in the act of drumming. The paralysis was evidently due to the over-use of a single muscle, and as it occurred only on the left side, we are not surprised to learn that in drumming the left hand is especially liable to strain. The mechanism is described as follows: The right hand is in a position of pronation with the dorsal surface directed upward; the right drumstick is held in the whole hand, as one would grasp a stick as a weapon; the wrist, 
elbow and shoulder all take part in the necessary movements. The left hand, however, plays usually only the accompaniment; it and the left forearm are supinated, the palm of the hand being directed upward. The drumstick is held between the thumb and index finger, and its movements call only for slight pronation and supination of the hand and wrist. The adductor pollicis is the chief muscle involved in holding the drumstick firmly in the above position, but the flexor longus pollicis has also an important role. It maintains the distal phalanx of the thumb in a state of strong flexion, so that it grasps the drumstick like a hook and prevents its slipping toward the ends of the fingers. This muscle remains, therefore, in a state of contraction throughout the whole time of practice.

The above description explains why the flexor longus pollicis should alone show the effects of over-use, though Bruns admits that we might well expect the adductor pollicis to show some fatigue also. The author has been unable to find any published cases similar to his, but he is informed by military surgeons that a number of such cases have been observed.

Bruns recognizes that his drummer's paralysis differs from the ordinary occupation neuroses in that it is of peripheral origin, while they are for the most part of central origin. But he thinks the distinction is often difficult to make in practice. Even in the best known of the occupation neuroses, namely, writer's cramp, there are some cases in which we find true paralysis with changes in electrical reaction of the affected muscles, thus pointing to a peripheral origin. J. W. B.

\section{ANASTHETIC FACIAL MONOPLEGIA.}

Adamkiewicz (ilid.) reports the following case of this rare affection: An officer, 5 I years of age, had noticed occasionally, for several years, a feeling of tickling and formication in the face, accompanied at times with burning pain ; also a tendency to catarrh, and uncontrollable sneezing. Objectively there was complete anæsthesia in the region of both fifth nerves, all branches being affected on the left side, the first and part of the second branch on the right side.

Adamkiewicz thought the lesion peripheral and diagnosed neuritis and perineuritis with ascending atrophy of both trigeminal nerves. J. W. B. 